\title{
Ética na engenharia civil
}

É essencial para o engenheiro ampliar uma visão sistemática do planeta, ou seja: saber que, como atuante de mudança social, ele é componente do todo. Neste aspecto, é efetivo dilatar capacidades científica e tecnológica com gestão moral. Ao assumir consciência da obrigação de harmonizar sua habilidade técnica com a habilidade humana, esse profissional aumentará a habilidade conceitual, a qual está diretamente integrada à constituição e conexão de todas as atividades, caráteres e interesses da organização à qual pertence ou presta serviço. Seja qual for à particularidade da engenharia, o seu profissional deve estar entrelaçado e empenhado com o presente e com o futuro da organização. É a partir dessa hipótese que está implantado o presente artigo, a qual objetiva expor uma reflexão sobre a força da Responsabilidade Social na formação do engenheiro. Procura-se no presente artigo ponderar os princípios que norteiam a Responsabilidade Social como uma plausível ajuda na gênese apropriada para os novos profissionais de engenharia.

Palavras-chave: Ética; Engenharia; Responsabilidade.

\section{Ethics in civil engineering}

It is essential for the engineer to expand a systematic view of the planet, that is: to know that, as an actor of social change, he is a component of the whole. In this respect, it is effective to expand scientific and technological capacities with moral management. When he becomes aware of the obligation to harmonize his technical skill with human skill, this professional will increase his conceptual skill, which is directly integrated into the constitution and connection of all activities, characters and interests of the organization to which he belongs or provides service. Regardless of the particularity of engineering, your professional must be intertwined and committed to the present and the future of the organization. It is from this hypothesis that the present article is implemented, which aims to expose a reflection on the strength of Social Responsibility in the training of engineers. This article seeks to consider the principles that guide Social Responsibility as a plausible help in the appropriate genesis for new engineering professionals.

Keywords: Ethic; Engineering; Responsibility.

Topic: Engenharia Civil

Reviewed anonymously in the process of blind peer.
Received: 17/12/2020

Approved: 10/03/2021
João Paulo Magalhães Zanon

Instituto Tocantinense Presidente Antônio Carlos, Brasil http://lattes.cnpq.br/4090634069565197 ipmzanon@hotmail.com

\section{Eduardo Gouveia Santiago Lage}

Instituto Tocantinense Presidente Antônio Carlos, Brasil

http://lattes.cnpq.br/4344949197847151

eduardogslage@gmail.com

Diogo Pedreira Lima

Instituto Tocantinense Presidente Antônio Carlos, Brasil http://lattes.cnpq.br/7967728577417186

http://orcid.org/0000-0002-3849-2587

diogo.lima@itpacporto.edu.br

\section{Referencing this:}

ZANON, J. P. M.; LAGE, E. G. S.; LIMA, D. P.. Ética na engenharia civil. Engineering Sciences, v.9, n.1, p.75-84, 2021. DOI: http://doi.org/10.6008/CBPC2318-3055.2021.001.0008 


\section{INTRODUÇÃO}

O engenheiro é o profissional que busca justapor conhecimentos empíricos, técnicos e científicos à inspiração e à alteração de estruturas, composições, produtos e métodos que se empregam para transformar recursos naturais e não naturais em formas amoldadas às necessidades do ser humano e do meio que o cerca. Um profissional capaz para trabalhar com modificações é indispensável aos dias atuais, pois se vive em um período de técnicas e mudanças corrigidas que atuam diretamente na percepção humana, cuja imagem se dá inteiramente no ambiente que o protege como a outrem. Desse modo, o engenheiro deve proporcionar um perfil procedente de uma formação generalista, humanista, crítica e reflexiva, e ser habilitado a aspirar e desenvolver novas tecnologias, incitando ao seu desempenho crítico e criativo na identificação e resolução de problemas, ponderando seus aspectos políticos, sociais, ambientais e culturais, com espectro ético e humanístico, em acolhimento às impetras da sociedade.

O Código de Ética Profissional, regido pela Resolução № 1002 - de Novembro/2002 - CONFEA, é o principal meio de boa conduta para que um profissional exerça sua profissão, possibilitando um bom comportamento de modo geral. As profissões são diferenciadas por seus competentes aspectos, pelo conhecimento científico e tecnológico que se congregam nas expressões artísticas que empregam e pelos resultados sociais, econômicos e ambientais do trabalho que concretizam as entidades, instituições e conselhos complementares da organização profissional, são também permeados pelos códigos éticos das profissões e participantes solidários em sua constante construção, adoção, exposição, preservação e aproveitamento. Como é padrão regulatório da Ética, para o bem-estar de uma população é indispensável que se aplique em todos os domínios de desempenho desta população, e atuar em contradição a essas normas, invariavelmente resulta em subversões e talvez agravos a alguma das partes. Ética profissional é um dos critérios mais estimados no mercado de trabalho. Ter uma boa conduta no espaço de trabalho pode ser o passaporte para uma carreira de sucesso. Não só na engenharia, mas em todas as áreas profissionais esse tema deve ter maior destaque na vida de qualquer profissional.

A engenharia civil é umas das atividades econômicas que mais intervém, direta ou indiretamente, no diálogo da coletividade. Ao mesmo tempo em que nutre aspectos regionais e individuais, a engenharia civil é globalizada.

A ética, neste contexto, é a melhor ferramenta para gerar a assistência social e de valorização deste ofício. Espera-se que o profissional de engenharia civil participe da construção social em prol de uma melhor direção à conduta humana. Diante de tantas notícias sobre a falta de ética na profissão, os engenheiros civis devem repensar sua função não só como profissional, mas também como cidadão que é, e que está à busca de uma sociedade melhor para si.

Este estudo tem como objetivo analisar a ética na engenharia civil e sua importância para a mesma, colocando o pesquisador diante de fatos que fundamentam o estudo. Para a realização desse trabalho foi utilizado como base à revisão bibliográfica e documental, a abordagem adotada foi a de natureza qualitativa, com abordagem teórica. Com isso as considerações que foram feitas ao final do estudo são importantes para 
que o profissional da engenharia tenha em mente a sua responsabilidade ética, profissional, social, moral e civil e constitucional.

\section{METODOLOGIA}

Ética

A ética vem do vocábulo ethos, um termo de origem grega que denota 'caráter moral' et al., a ética está integrada a um contíguo de valores morais que orientam a conduta humano em uma sociedade, desta forma a ética é uma reflexão da moral, de maneira científica, baseada, teórica e racional.

À luz do que esclarece o conceito de ética, muitas vezes, ou na sua maioria, a ética está consubstanciada à moral. Mas não é bem assim. A finalidade dos códigos morais é reger a conduta dos membros de uma comunidade, de acordo com princípios de conveniência geral, para garantir a integridade do grupo e o bem-estar dos indivíduos que o constituem. Assim, o conceito de pessoa moral se aplica apenas ao sujeito enquanto parte de uma coletividade. Entretanto, a ética é a disciplina crítico-normativa que estuda as normas do comportamento humano, mediante as quais o homem tende a realizar na prática de atos identificados com o bem.

Um dos fatores que sofre influência da ética é o procedimento organizacional, que segundo Robbins (2002), pode ser determinado como o estudo do comportamento humano dentro do trabalho, feito a partir de três fatores: indivíduo, grupo e estrutura, ou seja, avalia o indivíduo em suas ações, personalidades, atitudes, aprendizagem tanto de forma individualista quanto em grupo e seu comportamento, seguindo uma estrutura hierárquica dentro da organização.

A engenharia civil importa um dos campos de maior alcance das Engenharias, visto que trabalha com atividades alusivas à múltiplas funções e distintos segmentos como projeção, entendimento e execução em áreas distintas como, moradia, transporte, saneamento entre outras. De forma a conservar os métodos evolutivos, desenvolveu-se desde os tempos da antiguidade, na busca do aperfeiçoamento do conhecimento para que tornassem mais simples o desempenho dos trabalhos de construções, de grande intensidade para aquelas épocas.

Nesse período, "Não havia método científico nas construções, que eram baseadas no sistema de tentativa e erro, sendo numerosos os exemplos de colapso de estruturas" (HANSEN et al., 2011), proporcionalmente ao avanço da sua complexidade que objetiva a necessidade de maior demanda de conhecimentos para as saídas dos problemas, abrangendo assim também nos estudos no campo da engenharia. A evolução da engenharia civil e a composição dos estudos relacionados ao seu desenvolvimento estão de modo direto associado aos avanços da ciência e da tecnologia (MACEDO et al., 2016).

A sociedade faz uso absorvente dos métodos e aparatos tecnológicos ampliados para simplificar a vida e dar ao homem máximo tempo livre.

Francis Bacon e René Descartes, cujos pensamentos vigoram no embasamento dessa engenharia transformadora do planeta ampliaram o saber desse mundo pleno de elementos tecnológicos. Francis Bacon, 
rompendo com os pensadores de seu tempo, defendeu a ideia de que o resultado da Ciência precisaria ser sobreposto ao ofício do homem. Como alerta Pergorara (2002), esse deslumbramento levou-nos à ilusão de acreditar que uma tecnociência nos conduziria a uma sociedade mais feliz e melhor. Talvez dessa utopia tecnicista proceda ainda essa atinada crise mundial de valores que se vive.

Necessariamente, das quatro regras de Descartes, aquela que todo engenheiro reconhece obrigatoriamente é a de dividir cada dificuldade em tantas parcelas quanto seja plausível e indispensável para resolvê-la.

Morin (2001) aborda a realidade sob o enfoque da complexidade. Seu desígnio nesse novo julgamento é sensibilizar o homem contemporâneo para as deficiências que estão presentes no pensamento atual. É o paradigma da complexidade se objetando ao paradigma da simplicidade. Simplificar, equacionar e ordenar individualiza o paradigma da simplicidade e é fortemente contemplado pelas engenharias por depositar ordem no Universo, enquanto o paradigma da complexidade parece ter vindo para desarrumar a casa, abrindo pontos onde só existiam certezas.

O engenheiro trabalha não só com suas máquinas e seus cálculos, mas também com outros seres humanos dos quais ele está sujeita. São esses outros indivíduos, de idades, culturas, categorias sociais diferentes, que prezam valores, seguem regras morais, que vivem sob posturas éticas muitas vezes distintas e contraditórias. São chefes, gerentes, diretores, técnicos, clientes, fornecedores, estagiários, vendedores e as ilimitadas equipes da qual esse engenheiro faz parte ou que se a ele se subordinam, e que diferem muitas vezes tão fortemente umas das outras que, sem uma gerência apropriada, não obtêm atender prazos, cumprir metas, prestar o serviço certo; em resumo, alcançara finalidade ambicionada.

Sá (2013) classifica a profissão como o "exercício habitual de uma tarefa, a serviço de outras pessoas, insere-se no contexto da sociedade como uma atividade especifica", a pratica profissional segundo este autor traz "benefícios recíprocos a quem pratica e a quem recebe o fruto do trabalho, também exige, nessa relação à preservação de uma conduta condizente com os princípios éticos específicos". Quando esses princípios éticos específicos não são acatados, traz implicações para a entidade, assim, para entender essas consequências é preciso também constatar como ocorrem os comportamentos avaliados antiéticos nos domínios de forma explicita.

Segundo Paulo (2000), os vácuos éticos existentes nessas relações têm forte correlação com a fragilidade da ética pessoal que se intensifica segundo do autor pelo "excessivo interesse do indivíduo por si próprio, pelo individualismo exacerbado, pelo narcisismo desmedido e pelo frágil sentido de solidariedade".

Percebe-se com essa citação que o egoísmo destrói relações profissionais e com a sociedade em geral. Cabe ao profissional se ater ao que estudou e aprendeu no decorrer de sua vida acadêmica e colocar em pratica uma postura correta, ou seja, ética.

Para Flach (2007) no atual modelo de trabalho é possível perceber que o autoritarismo e a competitividade têm gerado stress nos indivíduos e falta de segurança, além da carência de transparência nas relações interpessoais que ocasionam falta de confiança que se somado aos comportamentos antiéticos, tornam-se elementos prejudiciais aos indivíduos e à própria organização. 
É essencial ter sempre em mente que há uma série de atitudes que não estão descritas nos códigos de todas as profissões, mas que são comuns a todas as atividades que uma pessoa pode desempenhar. Atitudes de generosidade e cooperação no trabalho em grupo, mesmo quando desempenhadas isoladamente em uma sala, fazem parte de um conjunto maior de atividades que dependem do bom desempenho desta. Uma atitude proativa, por exemplo, é não ficar limitado às tarefas requeridas, mas cooperar para o engrandecimento do trabalho, mesmo que passageiro.

Ética para os profissionais das carreiras tecnológicas, como a da engenharia, o mais basilar princípio é compreender a dimensão de que o saber obtido na profissão como a de engenharia e suas ações, deve estar voltado ao bem da humanidade e, portanto, saber harmonizar as ações e interesses pessoais aos interesses coletivos deve ser a preocupação primordial do profissional que espera caminhar na linha ética ao longo da sua carreira.

De acordo Victer (2016) um profissional do ramo da engenharia quer seja Técnico, Tecnólogo ou Engenheiro que eventualmente usa sua carreira para transgredir ou dar lastro a uma ação irregular, não só atua de maneira que tangencia a ética, mas também faz o uso indevido do nome da profissão perante a sociedade. Ou seja, ao agir desta maneira está promovendo uma ação que não só a si lhe impacta, mas que reflete negativamente para toda a profissão, em especial no conceito, respeito e confiança que a sociedade deposita nas carreiras de engenharia.

Embora a ética abordada, tenha características genéricas, sua aplicação se diversifica segundo o segmento organizacional e profissional. Isto é, ao mesmo tempo em que a ética profissional está centrada nas ações exercitadas nas atividades profissionais estão, também, voltadas para as empresas e organizações de uma maneira geral, incluindo-se, especialmente, as entidades de classe. Mesmo porque, as entidades de todos os ramos e portes, devem desenvolver-se de tal maneira, que a conduta ética dos seus participantes, assim como os valores e conviç̧ões das mesmas, torne-se parte de sua cultura (ARRUDA et al., 2001).

\section{DISCUSSÃO TEÓRICA}

\section{Ética profissional}

De acordo com os estudos sobre ética, de Edouard Delruelle, "o termo ética permite delimitar uma dimensão do comportamento que escapa à moral. É a dimensão subjetiva e ponderada dos valores e das normas; a forma como cada um se conduz, como cada um se define enquanto sujeito moral" (DELRUELLE, 2004).

Nesse caso podemos utilizar os termos, ética e moral para definir os comportamentos humanos e nada impede de se utilizar essas duas palavras dando-lhes sentidos diferentes. "A ética, tal como a entendemos, é o estudo lógico da linguagem da moral" (HARE, 1996).

De acordo Vázquez (2014), ética é a ciência do comportamento moral dos homens em sociedade. É uma ciência, pois tem elemento próprio, leis próprias e procedimento próprio, na simples identificação do caráter científico de um determinado ramo do conhecimento. O componente da Ética é a moral. A moral é 
um dos aspectos da conduta humana.

A moral disciplina o comportamento do homem consigo mesmo. Tratam dos costumes, deveres e modo de proceder dos homens com os outros homens, segundo a justiça e a equidade natural, ou seja, os princípios éticos e morais são na verdade os pilares da construção de uma identidade profissional e sua moral mais do que sua representação social contribui com a formação da consciência profissional. A ética é indispensável ao profissional, porque na ação humana 'o fazer' e 'o agir' estão interligados. 0 fazer diz respeito à competência, à eficiência que todo profissional deve possuir para exercer bem a sua profissão. 0 agir se refere à conduta do profissional, ao conjunto de atitudes que deve assumir no desempenho de sua profissão.

Segundo o site guia da carreira, ter ética profissional e adequar-se às normas de conduta de uma empresa são condições cada vez mais valorizadas no reconhecimento dos trabalhadores e no processo seletivo de novos funcionários. Para você conquistar uma vaga no mercado de trabalho e manter-se no emprego em longo prazo, é preciso mais que formação acadêmica e experiência profissional. Observa-se na citação acima o valor da ética profissional, assim, como o comportamento que, é parte da ética, para uma empresa e o profissional que a ela se submete. Ser capacitado e poder trabalhar em uma empresa que zela pela ética como um valor imprescindível faz com que seus profissionais se sintam membros de algo maior e que estão colaborando para um mundo melhor também. Por outro lado, quando sentem que seus valores éticos estão sendo feridos, sua motivação e produtividade baixam de maneira drástica. Portanto, o bom exemplo da organização faz com que sua equipe se sinta mais segura ao adotar suas decisões e mais confiante em sua liderança, pois sabe que os princípios por ela pregados são corretos e trazem um retorno positivo para todos.

Como gratificação, os colaboradores que igualmente cultivam a ética profissional no trabalho, por conseguinte, acabam sendo distinguidos de forma positiva pela sociedade por seu comportamento exemplar. A ética é, portanto, uma trabalhadora disciplinada que nunca descansa, pois a todo o tempo precisa-se recorrer a ela para jamais perder de vista valores e condutas decentes.

A ética no trabalho está diretamente relacionada à honestidade, pois não há como ser ético sem ser honesto. Entretanto, como se compreende no dia a dia de um profissional pode aparecer muitas circunstâncias onde à sua probidade e integridade são testadas. Para não sucumbir a nenhuma delas, é essencial contra-atacar, ou seja, distinguir e aperfeiçoar hábitos positivos e que andem na direção contraposta aos comportamentos imorais que muitas pessoas têm sem refletir nas implicações.

\section{$O$ código de ética do engenheiro civil}

No que se refere ao âmbito da engenharia civil como um todo, há de se considerar que o campo da ética na construção civil já foi aprofundado em diferentes países e mostrou que há um contraponto extremamente importante, ao mesmo tempo em que é o setor mais importante para o desenvolvimento econômico-social do país, é o que vem sendo considerado o setor mais tendencioso para o comportamento antiético (SOUTINHO et al., 2011). 
Estudos realizados em alguns países apontaram que a principal causa do comportamento antiético, está relacionada à competição, agravada pelas metas empresariais surreais e pelo fato dos profissionais se atentarem mais as questões financeiras. Considerou-se também que as questões antiéticas estão diretamente ligadas à quebra de confiança e integridade, a incidência de suborno segundo os estudos também foi apontada como um fator que contribui para a falta de ética, sendo habitual na indústria da construção civil, pois, esse problema de corrupção pode ocorrer sobre todas as fases de construção. A dimensão da corrupção na indústria da construção civil também é um fator alarmante (JONG et al., 2009, citado por SOUTINHO et al., 2011).

Carapeto et al. (2012) abordam que a ética na engenharia se diz respeito aos problemas que o engenheiro enfrenta no dia a dia, mas também interessa aos tomadores de decisão em geral e a todos os que são afetados pelas decisões técnicas. Essas condições éticas são iguais em todo o mundo, tendo em vista que a função do engenheiro sempre será a mesma independentemente de onde estiverem.

Sabe-se que o conceito de ética e, consequentemente, de ética profissional está muito mais voltado para um determinismo idealista do que propriamente realista. A realidade é que nem todo profissional, por inúmeros motivos, intrínsecos ou extrínsecos, é puramente ético, sendo assim, a filosofia moral contemporânea, considera que somente se poderá assegurar as condutas éticas a partir da aplicação da deontologia, que significa ciência do dever e da obrigação (OLIVEIRA, 2016).

Ainda segundo Oliveira (2016) o termo deontologia deriva do grego deontal (dever) e logos (razão). Considera-se que a deontologia seja a ética aplicada às situações profissionais, estabelecida através do conjunto normativo de imposições que deve coordenar uma atividade profissional. A deontologia determina que o mais importante seja cuidar com honestidade e competência pelo nome da profissão, tendo como base principal de normatização o Direito Constitucional, pois a responsabilidade maior do profissional enquanto ser homem é ser comprometido com o bem comum social.

Assim averiguando essas considerações da deontologia à luz da aplicabilidade da ética profissional dos engenheiros, Vieira (2015) elucida que os códigos deontológicos tendem a se atualizar com mais rapidez que os normativos legais e políticos, porém nenhum deles acompanha a velocidade do avanço tecnológico. Por isso é necessário o engenheiro utilizar, os princípios éticos de forma complementar a todas as normas impostas, para conseguir atingir os melhores resultados possíveis, no objetivo de viabilizar o desenvolvimento econômico, social e ambiental, tendo responsabilidade pelo uso dos recursos materiais finitos, dando condições para que as gerações futuras possam também obter todos esses objetivos.

Assim, considerando que de um lado o engenheiro detém total domínio dos conhecimentos técnicos e tecnológicos e de outro lado ele detém prioritariamente uma responsabilidade social em favor de sua especialidade, considera-se que as atribuições do engenheiro vão além dessa limitação técnica. Tanto é assim, que o próprio Código de ética do engenheiro no Art. 6ำ estabelece que o objetivo das profissões e a ação dos profissionais voltam-se para o bem-estar e o desenvolvimento do homem, em seu ambiente e em suas diversas dimensões.

O código de ética profissional da engenharia, da arquitetura, da agronomia, da geologia, da geografia 
e da meteorologia, coloca que seus princípios éticos devem envolver toda sua conduta honesta, digna e cidadã considerando que a sua finalidade é exercer o bem social, com base nos preceitos do desenvolvimento sustentável, tendo como primazia a melhoria da qualidade de vida do homem, por isso é de suma importância observar a eficácia e a segurança nos seus procedimentos e o relacionamento profissional honesto, justo e com espírito progressista dos profissionais para com os gestores, beneficiários e colaboradores de seus serviços, com igualdade de tratamento entre os profissionais e com lealdade na competição (CONFEA, 2002).

\section{A responsabilização das práticas antiéticas na engenharia civil}

Segundo Esser (2010), o Código Civil Brasileiro tem como fundamento a Responsabilidade Civil do engenheiro, à noção geral de uma obrigação que ocasiona para seu responsável o dever de reparar o dano, obrigação está de natureza pessoal, que transcorre da conduta lesiva praticada pelo agente. Os elementos característicos da responsabilidade civil constituem-se, pois, da lesão ao direito de outrem, advindo do comportamento do agente causador do dano, bem como o nexo de causalidade que fundamenta sua ocorrência.

No que tange à atuação do Engenharia Civil, haverá irresponsabilidade quando o agente atua precipitadamente ou sem prever integralmente os resultados de sua ação; haverá negligência, quando existe omissão voluntária de medidas necessárias à segurança e cujas consequências sejam previsíveis e cuja realização teria evitado o resultado danoso; e haverá imperícia, quando ocorre inaptidão ou conhecimento insuficiente do agente para a prática de determinado ato. Resumindo, é imprudente quem faz demais, é negligente quem faz de menos e da imperícia decorre o erro ou o fazer mal feito.

Assim para que surja a responsabilização é necessário que exista a conduta de um agente ou comportamento praticado por terceiro em casos determinados em lei. Ou seja, a responsabilidade por ato próprio se justifica no próprio princípio informador da teoria da reparação, pois se alguém, por sua ação pessoal, infringindo dever legal ou social, prejudica terceiro, é curial que deva reparar esse prejuízo

Considera-se assim, que a falta de ética na construção civil pode acarretar sérias consequências para o engenheiro ou até mesmo para construtora enquanto pessoa jurídica, como a cassação da licença de operação, multas, processos criminais e até mesmo a prisões. Por isso tem-se pensado em práticas para minimizar todas essas possibilidades, sobretudo atualmente, mediante a nova visão distorcida que a mídia vem apresentando sobre os engenheiros civis como mostrado anteriormente.

A ética no ambiente profissional contribui para garantir o bom andamento das atividades e favorecer o clima organizacional sadio e harmonioso, atuar profissionalmente com ética existirão vantagens intangíveis. Os engenheiros que fundamentam suas ações e comportamentos visando ao respeito e à cooperação também se beneficiam por um ambiente de trabalho ético. Criar e cultivar laços com outros funcionários e líderes, desenvolver uma reputação positiva e promover um ambiente de trabalho harmonioso certamente gerarão reflexos benéficos para a carreira de quem adota um rigoroso código de conduta profissional. Dessa forma, os funcionários passam a desenvolver mais confiança entre si, o que 
auxilia no aumento da produtividade.

\section{CONCLUSÕES}

A ética, nesta situação, é a melhor ferramenta para requerer a proteção social e de valorização desta carreira. Espera-se que o profissional de engenharia civil participe da construção social em prol de uma mais perfeita direção ao comportamento humano. Este profissional também necessita criar um pacto profissional, de um acordo decisivo grupal em torno das qualidades de convivência e relacionamento, apontando um comportamento profissional cidadã.

Um profissional apropriado para trabalhar com modificações é imprescindível aos dias atuais, pois se vive em um momento de técnicas e mudanças ajustadas que atuam transversalmente na inteligência humana, cuja representação se dá absolutamente no espaço que o abriga como a outrem. $O$ engenheiro deverá ter formação que o capacite a cogitar, arquitetar, identificar, analisar, interpretar, desenvolver, dirigir, supervisionar, gerenciar e executar as mais distintas atividades dentro da sua particularidade, rimordialmente aquelas que determinem um sólido fundamento científico e tecnológico ligado a informações essenciais em áreas do saber relacionados direta ou indiretamente às funções da engenharia com responsabilidade social, ética e respeito para com o outro e o meio em toda a sua magnitude.

Assim, o engenheiro deve apresentar um perfil procedente de uma formação generalista, humana, crítica e reflexiva, e ser habilitado a absorver e ampliar novas tecnologias, incitando seu comportamento decisivo e inventivo na assimilação e decisão de problemas, analisando seus aspectos políticos, sociais, ambientais e culturais, com alma ética e humanística, em acolhimento às demandas da coletividade.

Os profissionais devem voltar-se para o bem-estar e o desenvolvimento do homem, em seu ambiente e em suas diversas dimensões: como indivíduo, família, comunidade, sociedade, nação e humanidade. A profissão realiza-se pelo cumprimento responsável e competente dos compromissos profissionais, munindose de técnicas adequadas, assegurando os resultados propostos e a qualidade satisfatória nos serviços e produtos e observando a segurança nos seus procedimentos, esta é praticada através do relacionamento honesto e justo. São deveres do profissional: oferecer seu saber para o bem da humanidade, harmonizar os interesses pessoais aos coletivos, contribuir para preservação da incolumidade pública, divulgar os conhecimentos científicos, artísticos e tecnológicos inerentes à profissão.

As profissões são definidas através dos seus próprios perfis, pelo saber científico e tecnológico que se inserem nas expressões que utilizam e pelos resultados sociais, econômicos e ambientais do trabalho que realizam as entidades, instituições e conselhos integrantes da organização profissional, são igualmente permeados pelos preceitos éticos das profissões e participantes solidários em sua permanente construção, adoção, divulgação, preservação e aplicação. Como é padrão regulatório da Ética, para o bem-estar de uma população é necessário que se aplique em todas as esferas de atuação desta população, e agir em contradição a essas normas, resulta em conflitos e talvez danos a alguma das partes. 


\section{REFERÊNCIAS}

ARRUDA, M. C. C.; WHITAKER, M. C.; RAMOS, J. M. R.. Fundamentos da ética empresarial e econômica. São Paulo: Atlas, 2001.

CARAPETO, C.; FONSECA, F.. Ética e Deontologia: manual de formação. Cahiers du Lasmas, v.2, p.1, 2012.

CONFEA. Conselho Federal de Engenharia e Agronomia. Código de ética profissional da engenharia, da agronomia, da geologia, da geografia e da meteorologia. Brasília: CONFEA, 2002.

DELRUELLE, E.. Metamorfose do Sujeito: A ética filosófica de Sócrates a Focault. Lisboa: Instituto Piaget, 2004.

FLACH, L.. Comportamentos antiéticos nas organizações: relatos ligados a inveja, mentira, fofocas e assédio moral. In: ENCONTRO NACIONAL DA ASSOCIAÇÃO NACIONAL DE PÓS-GRADUAÇÃO EM ADMINISTRAÇÃO, 31. Anais. Rio de Janeiro: ANPAD, 2007.

HANSEN, K.; ZENOBIA, K.. Manual de prática profissional do engenheiro civil. Nova Jersey: John Wiley\& Sons, 2011.

HARE, R. M.. A linguagem da Moral. São Paulo: Martins Fontes, 1996.

MACEDO, G. M.; SAPUNARU, R. A.. Uma breve história da engenharia e seu ensino no Brasil e no mundo: foco Minas Gerais. REUCP, Petrópolis, v.10, n.1, p.42, 2016.
MORIN, E.. Introdução ao pensamento complexo. 3 ed. Lisboa: Instituto Piaget, 2001.

OLIVEIRA, A. R.. Ética profissional. 2016.

PAULO, F.. Ética nas organizações. 2000.

PERGORARA, O. A.. Ética e Bioética: da subsistência à existência. Petrópolis: Vozes, 2002.

ROBBINS, S. P.. Comportamento organizacional. São Paulo: Prentice Hall. 2002

SÁ, A. L.. Ética Profissional. 4 ed. São Paulo: Atlas, 2013.

SOUTINHO, F. A. A.; AZEVEDO, G. M. C.; COSTA A. J. D. R.. A ética na construção civil: evidência de Portugal (Conselho de Viseu). Instituto Superior de Contabilidade e Administração da Universidade de Aveiro, 2011.

VÁZQUEZ, A. S. Ética. Rio de Janeiro: Civilização Brasileira, 2014.

VICTER, W. G.; CARDOSO, B.. Crises geram oportunidades. Revista Conjuntura Econômica, v.63, n.12, 2016.

VIEIRA, J. L. N.. Aspectos práticos sobre ética e deontologia na engenharia. João Pessoa: Instituto de Pós-Graduação e Graduação - IPOG, 2015.

A CBPC - Companhia Brasileira de Produção Científica (CNPJ: 11.221.422/0001-03) detém os direitos materiais desta publicação. Os direitos referem-se à publicação do trabalho em qualquer parte do mundo, incluindo os direitos às renovações, expansões e disseminações da contribuição, bem como outros direitos subsidiários. Todos os trabalhos publicados eletronicamente poderão posteriormente ser publicados em coletâneas impressas sob coordenação da Sustenere Publishing, da Companhia Brasileira de Produção Científica e seus parceiros autorizados. Os (as) autores (as) preservam os direitos autorais, mas não têm permissão para a publicação da contribuição em outro meio, impresso ou digital, em português ou em tradução. 